\title{
Plasma effect on propagation of filamented femtosecond laser pulse in fused silica
}

\author{
Blonskyi I. ${ }^{1}$, Kadan V. ${ }^{1}$, Shpotyuk O. ${ }^{2}$ and Pavlov I. ${ }^{1}$ \\ ${ }^{1}$ Department of Photonic Processes, Institute of Physics NAS of Ukraine, \\ 46 Prospekt Nauky, 03028 Kyiv, Ukraine; E-mail: kadan@iop.kiev.ua \\ ${ }^{2}$ Scientific Research Company "Carat”, 202 Stryiska St., 79031 Lviv, Ukraine
}

Received: 17.03.2009

\begin{abstract}
Propagation of filamented femtosecond laser pulses in fused silica is studied using microscopic techniques of time-resolved femtosecond optical polarigraphy and transient absorption. Basing on the value of induced absorbance measured at the trailing edge of propagating pulse, it is concluded that the filament is refilled by energy flux from a reservoir. Light energy and plasma density in the filament core, along with the corresponding changes in refraction index, are estimated. Reshaping of the laser pulse caused by expulsion of light from the plasmaoccupied area is directly observed. Transformation of axially symmetric shape of the pulse into asymmetric Z-like one is also found.
\end{abstract}

Keywords: femtosecond laser pulses, Kerr effect, filaments, plasma, fused silica

PACS: 42.65.Re, 42.65.Jx, 52.38.Dx

UDC: 535.542

\section{Introduction}

If the power of laser pulse travelling in fused silica exceeds a critical value $P_{\text {cr }}(1.9 \mathrm{MW}$ [1] corresponding to the energy of $0.33 \mu \mathrm{J}$ at the conditions of $150 \mathrm{fs}$ pulse duration, the wavelength of $\lambda=780 \mathrm{~nm}$ and the nonlinear Kerr refractive index $n_{2}=3.2 \times 10^{-16} \mathrm{~cm}^{2} / \mathrm{W}$ ), then self-focusing and filamentation occur [2], changing drastically the pulse propagation mode. Therefore, studies of femtosecond filamentation are important both from the fundamental point of view and in view of possible applications such as micromachining, microsurgery, writing of bulk-embedded optical waveguides, etc. Till recently, two main approaches have dominated in theoretical modelling of femtosecond filamentation. The first one [3] considers the filament as a self-sustained structure governed by a balance between Kerr self-focusing and plasma defocusing. The second approach [4], a so-called "moving focus" model, regards the filament as an extended focus line, composed of selffocuses of different temporal slices of the laser pulse. Lately, the filamentation phenomenon has been reinterpreted on the basis of concept of a nonlinear X-wave, providing an energy flux to the filament core depleted by nonlinear losses. X-wave (also referred to as a Bessel or conical wave) is a wave packet whose wave vectors are spread in the simplest 
case along a cone surface, which propagates without undergoing natural spreading due to diffraction or dispersion. Recently it has been shown (see [5-7]) that X-waves are spontaneously generated in nonlinear media characterised with the both nonlinearities $\chi^{(2)}$ and

$\chi^{(3)}$ from conventional localised pulses. Actually, both in frame of the "moving focus" and the X-wave models the filament consists of narrow (several microns in diameter for solids) intense core containing about $10 \%$ of total energy. The rest of the energy is distributed in low-intensity "reservoir" of much bigger diameter extended around the core [8], nonlinear losses in the core being compensated by energy flux from the "reservoir".

Effect of plasma caused by influence of refraction decrease on spatial reshaping of the femtosecond pulse has been repeatedly simulated for fused silica $[9,10]$ in a wide range of beam powers under assumption of axial symmetry. It has been predicted in [11] that transverse pulse profile is shaped as a cone in space-time domain. Axial depletion of femtosecond laser pulses caused by nonlinear losses (NLL) and/or plasma expulsion of light from the area of reduced refraction has been experimentally observed in water [12] but, as far as we know, the effect has been never seen in solids and in the filamented mode.

In this work we are aiming at finding spatiotemporal parameters of filamentary propagation of $150 \mathrm{fs}, 780 \mathrm{~nm}, 2.9 \mu \mathrm{J}$ laser pulse in fused silica. In particular, we focus on plasma-induced pulse reshaping and NLL, which will be associated with the pulse configuration, thus checking applicability of the model of self-sustained propagation of the filament in fused silica. We hope that the results obtained should be useful both for potential technologies and for the appropriate choice of applicable modelling approach.

\section{Experimental}

Among various experimental methods [2], femtosecond time-resolved optical polarigraphy (FTOP) [13] directly visualises propagating light itself. Combination of FTOP and transient absorption (TA) microscopy within a single experimental setup allows us to perform a space-time mapping of both induced Kerr birefringence and induced plasma absorption (PA). A general scheme of our experiment is shown in Fig. 1. Regenerative amplifier 1 generates a train of horizontally polarised pulses $(2.5 \mathrm{~mJ}, 150 \mathrm{fs}$, $780 \mathrm{~nm}, 1 \mathrm{kHz}$ ). A $\lambda / 2$ retarder plate 5 and a Glan prism 6 produce vertically polarised pump beam of adjustable power. Variable aperture 7 cuts out a narrower beam before entering objective 8 with focal position inside a $3 \times 3 \times 50 \mathrm{~mm}^{3}$ polished sample 10 , made of KU-1 brand of fused silica of the former Soviet Union, at $1.5 \mathrm{~mm}$ depth from the front surface and $0.3 \mathrm{~mm}$ from the left-side surface.

The sample 10 is fixed on a 3D translation stage with motorised Z-axis and is translated vertically with the speed of $50 \mu \mathrm{m} / \mathrm{s}$ during the measurements. The aperture diameter $1.8 \mathrm{~mm}$ and the pump pulse energy $2.9 \mu \mathrm{J}$ (after the aperture inside the sample) were chosen to produce a single filament inside the bulk of silica. The objective 9 images the filament on a $1200 \times 1600$ matrix of monochrome CCD-camera with $4.4 \times 4.4 \mu^{2}$ pixel size and $0.4 \mu \mathrm{m} /$ pixel scale, resulting in $2 \mu \mathrm{m}$ spatial resolution. Variably delayed probe 
beam serves as a flash for time-resolved photos. Axis of a film polariser 11 is set at $45^{0}$ with respect to the vertical position. Axis of a polariser 12 could be set in both crossed and parallel positions with respect the polariser 11. The CCD-camera records the TA in the parallel position and the FTOP images in the crossed one.

In the case of crossed polarisers the pump pulse induces instant birefringence in the fused silica due to the Kerr effect: $n_{e}-n_{0}=I_{\text {pump }} n_{2}$, where $I_{\text {pump }}$ is the pump intensity. The area with the induced birefringence acts as a phase retarder, making polarisation of the probe light elliptical. The polarisation component orthogonal to the major axis of the ellipse survives the second polariser 12, producing the FTOP signal. If the phase shifts remain small and the condition $I_{\text {pump }}>>I_{\text {probe }}$ holds true (with $I_{\text {probe }}$ being the probe light intensity), the intensity of the FTOP signal may be written as [14] $I_{\text {FTOP }}=\pi^{2} d^{2} n_{2}^{2} I_{\text {pump }}^{2} I_{\text {probe }} / \lambda_{\text {probe }}^{2}$, where $d$ denotes the pump-probe interaction length and $\lambda_{\text {probe }}$ the probe wavelength. This simplified formula is valid for uniform and continuous interacting beams. Nevertheless, it shows that $I_{F T O P}$ is proportional to $I_{\text {pump }}^{2}$ and thus represents instantaneous pump intensity distribution.

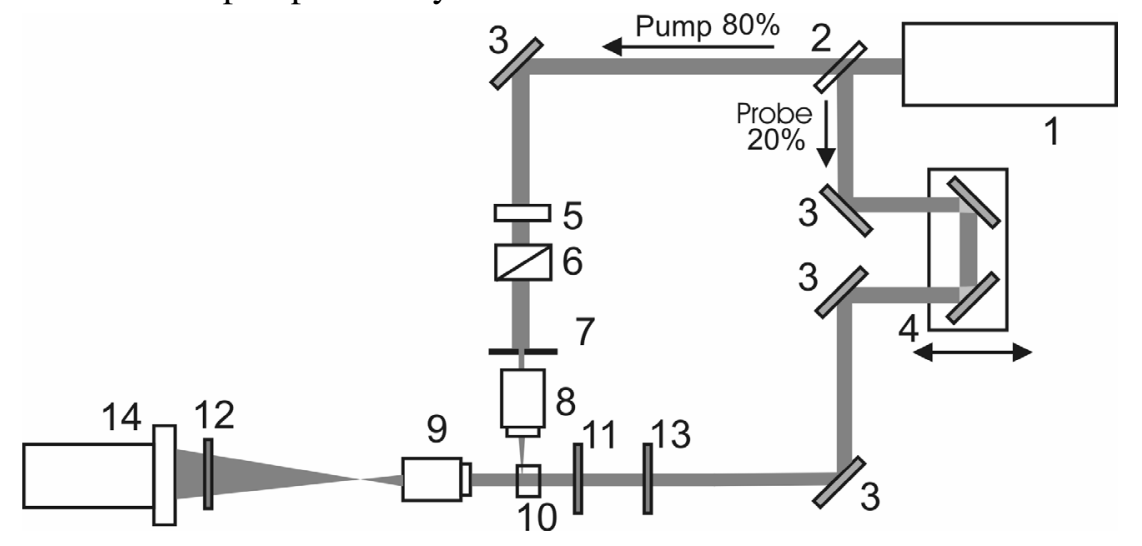

Fig. 1. General scheme of experimental setup: $1-$ femtosecond regenerative amplifier; 2 - splitting mirror; 3 - bending mirrors; 4 - delay line; $5-\lambda / 2$ retarder plate, 6 - Glan prism; 7 - variable aperture; 8, 9 - microscopic objective 10x, 0.25NA; 10 - fused silica sample; 11, 12 - film polarisers; 13 - grey attenuator filter; 14 - CCD-camera.

According to the more explicit expression for the FTOP image given in [15], the spatial intensity distribution is determined by convolution of the probe signal and the square of integral of intensity of the pump signal along the interaction direction $Y$. Note that the attempts to perform complete analysis of the FTOP images according to the model [15] are not among the subjects of the present work. Nonetheless, when interpreting the FTOP images, one should take into account the following factors: (i) non-zero probe duration causes blur of the moving object along the propagation axis in a manner similar to long expositions in common photography (in fact, the FTOP photo represents a convolution of the pump and probe pulses); (ii) the parameter $I_{F T O P}^{1 / 2}$ better represents the true picture 
of $I_{\text {pump }}$ distribution. Note also that the TA also affects the FTOP images. As a matter of fact, the FTOP photos are a superposition of the pure FTOP and TA.

\section{Results and discussion}

We have taken the FTOP and the related TA photos with $100 \mathrm{fs}$ increment of the delay $\tau$, beginning from $\tau=0$ and ending with $\tau=3.2 \mathrm{ps}$, thus covering $640 \mu \mathrm{m}$ propagation distance. Some noteworthy FTOP photos are shown in Fig. 2. In Fig. 2a partial transition to the filamented propagation mode is recorded, the full width at half maximum (FWHM) of the FTOP image being $3 \mu \mathrm{m}$ at the front edge and $8 \mu \mathrm{m}$ at the trailing edge. In Fig. $2 \mathrm{~d}$ one of the last positions is shown.

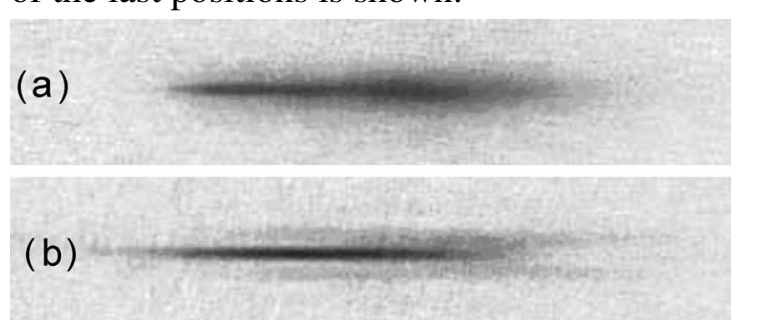

(c)

(d)

$$
20 \mu \mathrm{m}
$$

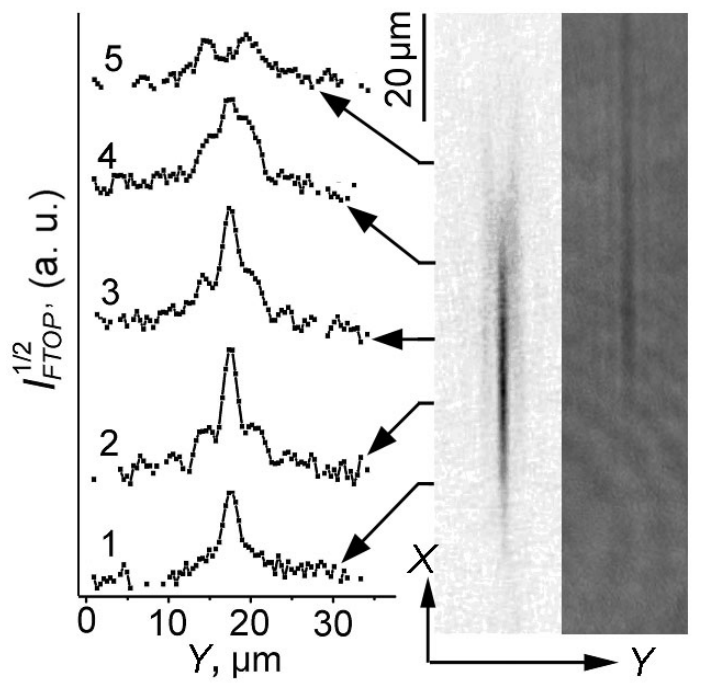

Fig. 2. Negative FTOP images of pump pulses propagating in fused silica from right to left at different delays $t$ in ps: (a) - 0.6; (b) - 1.3; (c) - 1.8; (d) - 3.0.

Fig. 3. FTOP image at $t=1.3 \mathrm{ps}$ delay and transversal intensity profiles ( 1 to 5 ) taken at the positions indicated by double bars.

The image of Fig. $2 b$ is analysed in Fig. 3. The signal has a pure narrow core of $3 \mu \mathrm{m}$ diameter at the leading edge (profile 1), acquiring slightly asymmetric volcano-like envelope towards the middle (profiles 2 and 3). In profile 4 the envelope dominates. It persists after termination of the core peak in a fork-like form. Notice that the only nonlinear reabsorption mechanism cannot explain 50\% axial dip in the profile 5. The maximum induced 
absorption makes $20 \%$ at the $X$ position of the profile 5 (see Fig. 4 below), causing $20 \%$ absorption of $I_{F T O P}$ and, hence, $10 \%$ weakening of $I_{F T O P}^{1 / 2}$. Thus, only small fraction of the observed dip can be explained by the reabsorption of the FTOP signal. In our opinion, the axial depletion of the FTOP signal is mainly caused by expulsion of excitation light from the low refraction area of plasma core. Indeed, generation of free carriers in the core of femtosecond filaments is a well-established fact [2]. The TA images and the absorption profiles presented in Fig. 3 and Fig. 4 confirm a presence of absorbing plasma in the filament core, which becomes apparent as a decaying tail persisting after the pulse termination. The estimations made below also corroborate this assumption, showing that negative plasma-caused change in the refractive index is equal approximately to $\Delta n_{p}=0.006$.
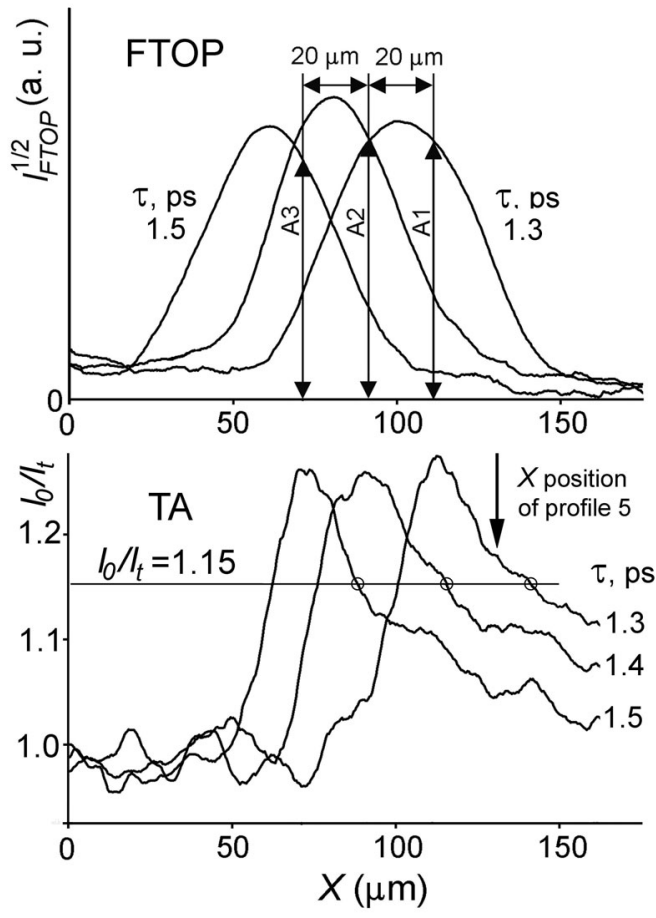

Fig. 4. Consecutive on-axis profiles of $I_{F T O P}^{1 / 2}$ (upper) and the related profiles of $I_{0} / I_{t}$ of the filament at $t=1.3,1.4$ and $1.5 \mathrm{ps}$. The pulse propagates from right to left. A1, A2 and A3 are the values of on-axis intensity at the $X$ positions corresponding to the TA maximum.

In Fig. 2c plasma-caused pulse reshaping results in an asymmetric double-bended Zlike shape. Probably, the self-focusing instability enhances a slight original asymmetry of cylindrical enveloping structure around the core, finally producing the observed shape. In any case, the effect of light expulsion from the filament core is even more pronounced in Fig. 2c, when compare with Fig. 2b. This observation indicates insufficiency of the assumption of axial symmetry used in the simulations of ultrashort pulse propagation [810]. Beginning from the delay $\tau=2.2 \mathrm{ps}$, the asymmetry gradually disappears, relaxing again to the cylindrical symmetry (see Fig. 2d). 
Let us now consider the on-axis profiles of $I_{F T O P}^{1 / 2}$ and $I_{0} / I_{t}$, aiming at finding NLL in the filament core and their influence on the pulse intensity. Fig. 4 represents three pairs of the associated FTOP and TA profiles taken at $\tau=1.3,1.4$ and $1.5 \mathrm{ps}$. Here two plots representing the $I_{F T O P}^{1 / 2}$ intensity profiles (upper) and the ratios of the initial $\left(I_{0}\right)$ to the transmitted $\left(I_{t}\right)$ probe intensities (lower) have a common $X$ axis. As follows from Fig. 4, the TA reaches its maximum in about $50 \mathrm{fs}(10 \mu \mathrm{m})$ after the maximum of $I_{F T O P}^{1 / 2}$ for every three $\tau$ values. The delayed tail persisting after the pump pulse termination is a signature of PA, though besides inversed Bremsstrahlung in plasma, TA also contains a component of multi-photon absorption (MPA), involving five pump and one probe photons for the wavelength of $780 \mathrm{~nm}$ in fused silica. Its maximum coincides with that of the pulse intensity and comes to the end with termination of the excitation pulse. Evidently, the maximum of the PA component is delayed in comparison with that of the pump pulse because of non-zero plasma lifetime, which also causes a delay of the maximum of the total TA profile.

It is evident that, in addition to the probe, the TA affects also the pump pulse itself, causing its NLL. Below we examine the TA-caused weakening of the filamented pulse, using the measured $I_{0} / I_{t}$ value as a lower limit. The actual absorption of the pump pulse is even higher for the following reasons: (i) the convolution blurring decreases $I_{0} / I_{t}$ in the resulting picture, and (ii) the MPA component of the TA for the pump is higher than that for the probe, because of the absence of polarisation mismatch between the participating photons in the former case. Not being able to take into account the exact distribution of plasma density and the pump intensity along $Y$ axis, we have calculated the effective absorbance $\alpha_{\text {eff }}=\ln \left(I_{0} / I_{t}\right) / d$, assuming that the absorption length (i.e., the FWHM of the transversal TA profile) amounts to $d=3 \mu \mathrm{m}$. In that case $\alpha_{\text {eff }}$ is $0.082,0.077$ and $0.077 \mu \mathrm{m}^{-1}$ respectively for the maxima of $I_{0} / I_{t}$ equal to $1.28(\tau=1.3 \mathrm{ps}), 1.26(\tau=1.4 \mathrm{ps})$ and $1.26(\tau=1.5 \mathrm{ps})$ (see Fig. 4). The above values of $\alpha_{\text {eff }}$ would cause significant weakening of the trailing part of the pulse if self-sustained (without external energy refilling) propagation of the filament is assumed. Indeed, the absorption factors $e^{\alpha_{e f f} l}$ would be respectively 27, 22 and 22 for the propagation distance $l=c \Delta \tau / n, \Delta \tau=0.2$ ps $(l=40 \mu \mathrm{m})$ and the values of $\alpha_{\text {eff }}$ quoted above. These high absorption factors would cause almost complete disappearance of the trailing edges at the $X$ positions of the maximum TA after $40 \mu \mathrm{m}$ propagation distance and, consequently, strong reshaping of the FTOP intensity profiles. On the contrary, no perceptible transformation of the axial profile of the FTOP signal is observed in the experiment after $40 \mu \mathrm{m}$ propagation distance (see Fig. 4): $\mathrm{A} 1 / \mathrm{A} 3=1.09$ at $\Delta \tau=0.2$ ps.

These data unambiguously confirm that the filament is not a self-sustained structure propagating without diffraction and perceptible energy losses, and that there is an external energy flux to the filament core, refilling the energy losses. Without the flux the filament could not survive so high NLL, even at the propagation distances as small as $40 \mu \mathrm{m}$ 
( $0.2 \mathrm{ps}$ in the time domain), letting alone the total $500 \mu \mathrm{m}$ propagation distance in the filamented mode observed in the experiment.

Let us now estimate the maximum electron density $\rho$ and the plasma-caused diminution of the refraction index $\Delta n_{p}$ from the TA data, using the Drude formulations for crosssection of inversed Bremsstrahlung [2] as a mechanism of light absorption in plasma:

$$
\sigma=e^{2} \tau_{c} / \varepsilon_{0} m^{*} c n_{0}\left(1+\omega^{2} \tau_{c}^{2}\right),
$$

where $e$ is the electron charge, $\tau_{c}$ the electron collision time, $\varepsilon_{0}$ the dielectric permittivity of free space, $m^{*}$ the reduced electron-hole mass and $\omega$ the probe light frequency. Accordingly, the refraction index change is given by $\Delta n_{p}=-\rho / 2 \rho_{c}$, with $\rho_{c}=\varepsilon_{0} m_{e} \omega^{2} / e^{2}$ [2].

To select a correct $I_{0} / I_{t}$ value for the estimations, one should exclude the MPA component of the TA. Therefore, basing on the TA data of Fig. 4, we assume that $I_{0} / I_{t}=1.15$. This is a value that corresponds to the trailing edge of the pulse. The positions corresponding to $I_{0} / I_{t}=1.15$ are shown by open circles on the TA profiles represented in Fig. 4. They are delayed by $38 \mu \mathrm{m}$ (190 fs), $34 \mu \mathrm{m}$ (170 fs) and $28 \mu \mathrm{m}(140 \mathrm{fs})$ with respect to the positions of FTOP maxima for $\tau=1.3,1.4$ and $1.5 \mathrm{ps}$, respectively. Hence, we can be sure that the portion of the MPA in the total TA is small in comparison with the PA at these positions. Assuming also the 3- $\mu \mathrm{m}$ absorption length (the FWHM of the TA profiles) and using the data $[16,17]$ for $\tau_{c}$ and $m^{*}$, we have estimated from Eq. (1) the average plasma density in the 3- $\mu \mathrm{m}$-diameter filament core as $\rho=7.5 \times 10^{19} \mathrm{~cm}^{-3}$ and the average refraction index change as $\Delta n_{p}=0.006$ at the $X$ positions indicated by open circles in Fig. 4.

Note that the visible extinction of the probe in the filament can, in principle, be a result not only of the true PA, but of the probe scattering at the refraction index variations as well. We have estimated a posteriori that the full scattering angle of the probe light at the index variations $\Delta n_{p}=0.006$ is close to $0.23^{0}$, i.e. much smaller than the objective aperture angle. Therefore the objective collects all the scattered light, producing no distortion of the resulting image.

\section{Conclusion}

In summary, we have observed formation of fork-like structure at the trailing edge of filamented femtosecond pulse caused by generated plasma. Breaking of axial symmetry of the pulse has also been recorded. Estimations of the NLL and the energy localised in the filamented part of the pulse corroborate the concept of filament refilling by energy flux from the reservoir.

\section{Acknowledgement}

The authors acknowledge partial financial support from the Science and Technology Center in Ukraine under the Project \#3745. We are also grateful to P. Korenyuk and O. Filin for their technical support. 


\section{References}

1. Kudriašov V, Gaižauskas E and Sirutkaitis V, 2005. Beam transformation and permanent modification in fused silica induced by femtosecond filaments. J. Opt. Soc. Am. B. 22: 2619-2627.

2. Couairon A and Mysyrowicz A, 2007. Femtosecond filamentation in transparent media. Phys. Rep. 441: 47-189.

3. Braun A, Korn G, Liu X, Du D, Squier J and Mourou G, 1995. Self-channeling of high-peak-power femtosecond laser pulses in air. Opt. Lett. 20: 73-75.

4. Brodeur A, Chien C Y, Ilkov F A, Chin S L, Kosareva O G and Kandidov V P, 1997. Moving focus in the propagation of ultrashort laser pulses in air. Opt. Lett. 22: 304-306.

5. Dubeitis A, Gaižauskas E, Tamošauskas G and Di Trapani P, 2004. Light filaments without self-channeling. Phys. Rev. Lett. 92: 253903-1-4.

6. Kolesik M, Wright E M and Moloney J L, 2004. Dynamic nonlinear X-waves for femtosecond pulse propagation in water. Phys. Rev. Lett. 92: 253901-1- 4.

7. Blonskyi I, Kadan V, Shpotyuk O and Dmitruk I, 2009. Opt. Commun. 1913-1917 (at press) DOI 10.1016/j.optcom.2009.01.056.

8. Mechain G, D'Amico C, Andre Y-B,Tzortzakis S, Franko M, Prade B, Mysyrowicz A, Couairon A, Salmon E and Sauerbrey R, 2005. Length of plasma filaments created in air by a multiterawatt femtosecond laser. Opt. Commun. 247: 171-180.

9. Ishikawa K, Kumagai $\mathrm{H}$ and Midorikawa K, 2002. High-power regime of femtosecond-laser pulse propagation in fused silica: Multiple cone formation. Phys. Rev. E. 66: $056608-1-8$.

10. Liu Y, Jiang H and Gong Q, 2006. Spatiotemporal transformation of a focused femtosecond pulse in the absence of self-focusing. Opt. Lett. 31: 832-834.

11. Polesana P, Franco M, Couairon A, Faccio D and Di Trapani P, 2008. Filamentation in Kerr media from pulsed Bessel beams. Phys. Rev. A. 77: 043814-1-11.

12. Faccio D, Matijosius A, Dubeitis A, Piskarskas R, Varanavičius A, Gaizauskas E, Piskarskas A, Couairon A and Di Trapani P, 2005. Near- and far-field evolution of laser pulse filaments in Kerr media. Phys. Rev. E. 72: 037601-1-4.

13. Kumagai H, Cho S-H, Ishikawa K, Midorikawa K, Fujimoto M, Aoshima S and Tsuchiya $\mathrm{Y}, 2003$. Observation of the complex propagation of a femtosecond laser pulse in a dispersive transparent bulk material. J. Opt. Soc. Am. B. 20: 597-602.

14. Takeda J, Nakajima K, Kurita S, Tomimoto S, Saito S and Suemoto T, 2000. Timeresolved luminescence spectroscopy by the optical Kerr-gate method applicable to ultrafast relaxation processes. Phys. Rev. B. 62: 10083-10087.

15. Fujimoto M, Aoshima S, Hosoda M and Tsuchiya Y, 2001. Analysis of instantaneous profiles of intense femtosecond optical pulses propagating in helium gas measured by using femtosecond time-resolved optical polarigraphy. Phys. Rev. A. 64: 033813-11. 
16. Zergioti I, Kyrkis K D, Papazoglou D G and Tzortzakis S, 2007. Structural modifications in fused silica induced by ultraviolet fs laser filaments. Appl. Surf. Sci. 253: 7865-7868.

17. Couairon A, Sudrie L, Franco M, Prade B and Mysyrowicz A, 2005. Filamentation and damage in fused silica induced by tightly focused femtosecond laser pulses. Phys. Rev. B. 71: 125435-1-11.

\begin{abstract}
Анотація. Розповсюдження філаментованих фемтосекундних лазерних імпульсів в плавленому квариі вивчалося із застосуванням мікроскопічних методик фемтосекундної часороздільної оптичної полярографії і індукованого поглинання. Виходячи з величини наведеного поглинання, виміряного на хвостовій частині імпульсу зроблено висновок про наявність потоку енергї з резервуару в ядро філаменту. Зроблено оцінку енергії світла і густини плазми в ядрі філаменту. Прямо зареєстровано зміну форми лазерного імпульсу внаслідок виштовхування світла з області, зайнятою плазмою. Також зареєстровано перехід початкової форми імпульсу з осьовою симетрією в асиметричну Z-подібну форму.
\end{abstract}

